\title{
Olho seco: etiopatogenia e tratamento
}

\author{
Dry eye: etiopathogenesis and treatment
}

\author{
Ellen Carrara Fonseca ${ }^{1}$ \\ Gustavo Viani Arruda ${ }^{2}$ \\ Eduardo Melani Rocha ${ }^{3}$
}

Trabalho realizado no Departamento de Oftalmologia da Faculdade de Medicina de Marília - FAMEMA Marília (SP) - Brasil e no Departamento de Oftalmologia da Faculdade de Medicina de Ribeirão Preto - USP - Ribeirão Preto (SP) - Brasil.

${ }^{1}$ Médica Voluntária do Departamento de Oftalmologia da Faculdade de Medicina de Marília - FAMEMA Marília (SP) - Brasil.

${ }^{2}$ Médico Radioterapêuta da Faculdade de Medicina de Marília; Pós-graduando (Doutorado) da Faculdade de Medicina de Ribeirão Preto da Universidade de São Paulo - USP - Ribeirão Preto (SP) - Brasil.

${ }^{3}$ Professor Associado do Departamento de Oftalmologia, Otorrinolaringologia e Cirurgia de Cabeça e Pescoço da Faculdade de Medicina de Ribeirão Preto da USP - Ribeirão Preto (SP) - Brasil.

Endereço para correspondência: Ellen Carrara Fonseca. Rua 24 de dezembro, 250 - Marília (SP) CEP 17500-090 E-mail: ellencarrara@gmail.com

Recebido para publicação em 30.03.2009

Última versão recebida em 03.12.2009

Aprovação em 19.12.2009

Os autores não possuem interesse comercial ou financeiro em nenhum produto mencionado no presente manuscrito.

Nota Editorial: Depois de concluída a análise do artigo sob sigilo editorial e com a anuência das Dras. Amélia Kamegasawa e Mônica de C. Alves Paula sobre a divulgação de seus nomes como revisoras, agradecemos suas participações neste processo.

\section{RESUMO}

Olho seco é uma doença multifatorial das lágrimas e da superfície ocular que resulta em desconforto, distúrbios visuais e instabilidade do filme lacrimal. É uma desordem comum que afeta principalmente adultos e mulheres e que pode causar impacto na qualidade de vida comparável a enxaqueca, dispnéia e insuficiência renal crônica, dependendo dos sintomas ou complicações que a acompanham. Novos conceitos com relação à fisiopatologia, classificação e tratamento têm sido apresentados e devem ser conhecidos pelos oftalmologistas pela sua larga aplicação no dia-a-dia. Estima-se que haja 100 medicações diferentes em uso para olho seco atualmente, além de outros métodos de tratamento, sendo necessário se estabelecer o que é realmente seguro e eficaz. Este texto faz uma revisão sobre etiopatogênese e tratamento da síndrome do Olho Seco.

Descritores: Síndrome do olho seco/terapia; Ceratoconjuntivite sicca/terapia; Doenças da córnea/terapia

\section{INTRODUÇÃO}

De acordo com consensos recentes, olho seco ou ceratoconjuntivite sicca (KCS) é uma doença multifatorial das lágrimas e da superfície ocular que resulta em desconforto, distúrbios visuais e instabilidade do filme lacrimal, com dano potencial à superfície ocular ${ }^{(1)}$. É acompanhado de aumento da osmolaridade do filme lacrimal e inflamação da superfície ocular ${ }^{(2-3)}$.

O desenvolvimento desta síndrome ou doença possui duas fases: na primeira, um ou mais estímulos ambientais iniciam, em indivíduos susceptíveis, a agressão aos tecidos envolvidos. Na segunda, os desdobramentos, sejam neuropáticos, metabólicos e/ou inflamatórios levam à instabilidade do filme lacrimal, à diminuição da secreção lacrimal, aumento da evaporação ou alteração da composição da lágrima. As repercussões na superfície ocular seguem a perpetuação desse processo.

Trata-se de desordem comum, afetando uma porcentagem significativa da população, principalmente adultos acima de 40 anos e mulheres. A prevalência é similar em todo o mundo, com taxas variando entre $7 \%$ e $33 \%{ }^{(4-5)}$.

Embora haja portadores assintomáticos, a maioria tem como principais sintomas sensação de corpo estranho, queimação, prurido, fotofobia, embaçamento visual e lacrimejamento excessivo, o que pode causar impacto na qualidade de vida. Possíveis complicações relacionadas à doença incluem ceratite, úlcera corneal, neovascularização, afinamento e até mesmo perfuração da córnea.

A estrutura do filme lacrimal foi recentemente revista e passou a ser considerada como composta por duas camadas (Figura 1):

- uma fina camada lipídica superficial produzida principalmente, mas não só, pelas glândulas meibomianas ${ }^{(6)}$; sua principal função é retardar a evaporação e manter o filme lacrimal uniforme sobre a superfície; 


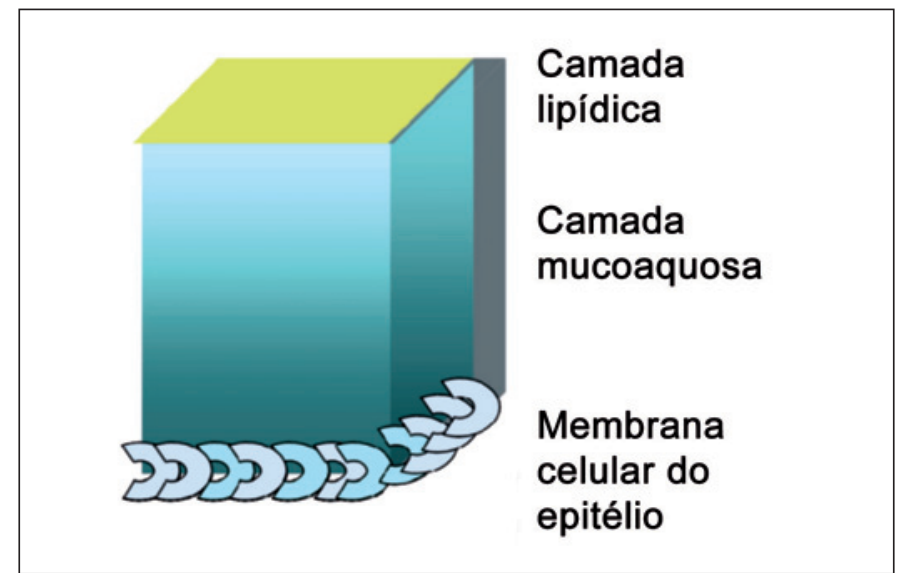

Figura 1 - Estrutura ilustrativa do filme lacrimal indicando, acima da membrana celular do epitélio da córnea, uma camada com muco de densidade regressiva à medida que se afasta da superfície e uma camada lipídica mais superficial

- uma camada interna mais espessa contendo muco diluído que se vai se concentrando em direção ao epitélio. De acordo com essa constatação, a fração aquosa não produz uma camada intermediária delimitada, como era anteriormente proposto ${ }^{(7)}$.

As alterações patológicas na composição da lágrima resultam de disfunção da Unidade Funcional Lacrimal (LFU: Lacrimal Functional Unity), a qual consiste de um sistema integrado que inclui as glândulas lacrimais, a superfície ocular (córnea, conjuntiva e glândulas meibomianas), as pálpebras e os nervos sensoriais e motores que as integram. A LFU mantém a superfície ocular saudável através do funcionamento adequado do filme lacrimal, que confere proteção, lubrificação e ambiente adequado para renovação de células epiteliais da córnea ${ }^{(8-9)}$; responde a influências ambientais, endocrinológicas e hormonais (Figura 2).

\section{FISIOPATOGENIA}

Hiperosmolaridade é a alteração na composição da lágrima que ocorre na maioria dos casos de olho seco. É referida como padrão-ouro para o diagnóstico de olho $\operatorname{seco}^{(10)}$ e reconhecida como estímulo pró-inflamatório no desenvolvimento da doença. Resulta em diferenciação anormal e perda acelerada das células epiteliais da superfície ocular, levando à instabilidade do filme devido à ausência do glicocalyx produzido por estas células, com consequente perda da camada hidrofílica na superfície corneal, e em alteração na barreira antimicrobiana. Além disso, a perda das células epiteliais deixa as terminações nervosas corneais expostas a insultos ambientais, levando ao desconforto ocular crônico.

Inflamação da superfície ocular pode ser tanto causa como consequência do olho seco: a disfunção das glândulas lacrimais altera a composição da lágrima, levando a um estado de hiperosmolaridade e estimulando a produção de mediadores inflamatórios, que por sua vez levam à disfunção das glândulas secretórias. O processo inflamatório pode também ser desen-

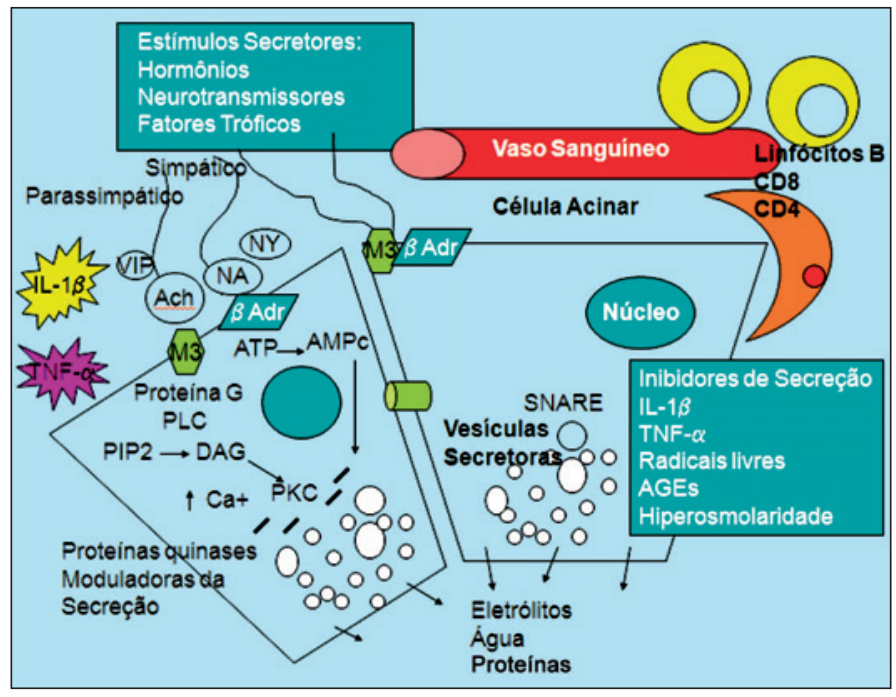

Figura 2 - Mecanismos fisiopatológicos envolvidos no funcionamento da secreção pelas células acinares da glândula lacrimal. Estímulos secretores estimulam (desencadeiam) uma cascata de sinalização intracelular que leva a transcrição de fatores e mediadores da secreção. Estímulos inibidores inibem (diminuem) a secreção e iniciam ou perpetuam a inflamação e mecanismos de morte celular.

cadeado por estresse irritativo crônico, como uso de lentes de contato, e doenças sistêmicas autoimunes (Figura 2).

Independentemente do estímulo inicial, portanto, ocorre um ciclo vicioso inflamatório na superfície ocular, levando à gradual disfunção das células responsáveis pela secreção ou retenção da lágrima.

Outro fator atualmente reconhecido na patogênese do olho seco é o estresse oxidativo, com liberação de radicais livres e espécies reativas ao oxigênio que podem causar apoptose e necrose celular. O stress oxidativo tem sido associado a várias condições sistêmicas, como doenças neurodegenerativas, cardiovasculares e câncer, além de atuar em doenças oculares como degeneração macular relacionada à idade, catarata, uveíte, retinopatia da prematuridade e alterações corneanas. A lesão celular causada pelos radicais livres é resultante de peroxidação lipídica das membranas, modificação oxidativa de proteínas e dano oxidativo ao $\mathrm{DNA}^{(11)}$.

Há ainda indícios de que o estresse oxidativo relacionado ao estado de hiperglicemia em casos de diabetes mellitus e resistência à insulina esteja envolvido na produção das alterações histológicas encontradas na glândula lacrimal de ratos, caracterizadas por mudanças na morfologia e acúmulo de inclusões semelhantes a lipofuscina ${ }^{(12)}$.

As variações fisiológicas que se desenvolvem com o envelhecimento também estão envolvidas na gênese do olho seco e incluem diminuição de volume e fluxo lacrimal, aumento da osmolaridade, perda da estabilidade do filme lacrimal e alterações na composição lipídica das glândulas de Meibômio. Mulheres na menopausa têm maior chance de desenvolver o quadro, provavelmente devido à diminuição na produção de andrógenos e estrógeno, com disfunção das glândulas meibomianas, e aos fatores relacionados à idade. 
De acordo com o "Dry Eye Workshop" (DEWS), a classificação de olho seco é dividida em três partes, baseadas em etiologia, mecanismos e estágio da doença, e distingue duas principais categorias: estado de deficiência aquosa e estado evaporativo (Figura 3$)^{(13)}$.

A deficiência de produção aquosa é subdividida em:

- Síndrome de Sjögren, primária ou secundária;

- Não associada à síndrome de Sjögren, tendo como causas: deficiência da glândula lacrimal, obstrução do ducto lacrimal, hiposecreção reflexa e uso de medicamentos sistêmicos.

Na deficiência de produção lacrimal, o olho seco é resultante da diminuição da secreção e do volume lacrimal, secundária à destruição ou disfunção dos ácinos glandulares. Isso leva à hiperosmolaridade da lágrima e, consequentemente, das células epiteliais da superfície ocular, desencadeando uma cascata de eventos inflamatórios envolvendo MAPquinases (Proteinoquinase Ativada por Mitógenos) e NFkB (Fator Nuclear de Cadeia Leve Kappa potenciador de células ativadas B) e gerando citocinas inflamatórias (Interleucina- $1 \alpha$, Interleucina- $\beta$ ), TNF (Fator de Necrose Tumoral) e metaloproteinases de matriz extracelular (MMP-9) ${ }^{(14)}$.

Quando a disfunção lacrimal é resultante de infiltração ou inflamação da glândula lacrimal, mediadores inflamatórios ganham a lágrima e se espalham pela superfície ocular. Não se sabe ao certo se as alterações na superficie ocular são causadas por ação direta dos autoantígenos ou secundárias aos agentes inflamatórios presentes na lágrima.
Na deficiência aquosa relacionada à síndrome de Sjögren a glândula lacrimal é infiltrada por células $\mathrm{T}$ ativadas que destroem suas células acinares e ductulares, diminuindo a secreção lacrimal. O processo inflamatório nas glândulas leva à expressão de autoantígenos na superfície das células epiteliais (fodrin, Ro e La) e retenção de células CD-4 e CD-8 tecidoespecíficas. Além disso, a hiposecreção é amplificada através de um bloqueio neurossecretor contra receptores muscarínicos dentro das glândulas ${ }^{(15)}$.

Há duas formas de síndrome de Sjögren $(S S)^{(16)}$ :

Primária: ocorrência de olho seco acompanhado de boca seca na presença de autoanticorpos, evidência de secreção salivar reduzida e biópsia de glândulas salivares menores positiva.

Secundária: características de SS primária associadas à evidência de outra doença autoimune do tecido conectivo, como artrite reumatóide, que é a mais comum, lupus eritematoso sistêmico, poliarterite nodosa, granulomatose de Wegener, esclerose sistêmica, esclerose biliar primária ou doença mista do tecido conjuntivo.

Os agentes desencadeadores do dano autoimune ainda não estão completamente esclarecidos, mas fatores de risco identificados incluem perfil genético (alta prevalência de HLA-B8), deficiência de hormônios sexuais (andrógeno e estrógeno), exposição a agentes ambientais (desde infecções virais até poluição ambiental) e deficiência de ômega-3 e outros ácidos graxos e vitamina $\mathrm{C}$.

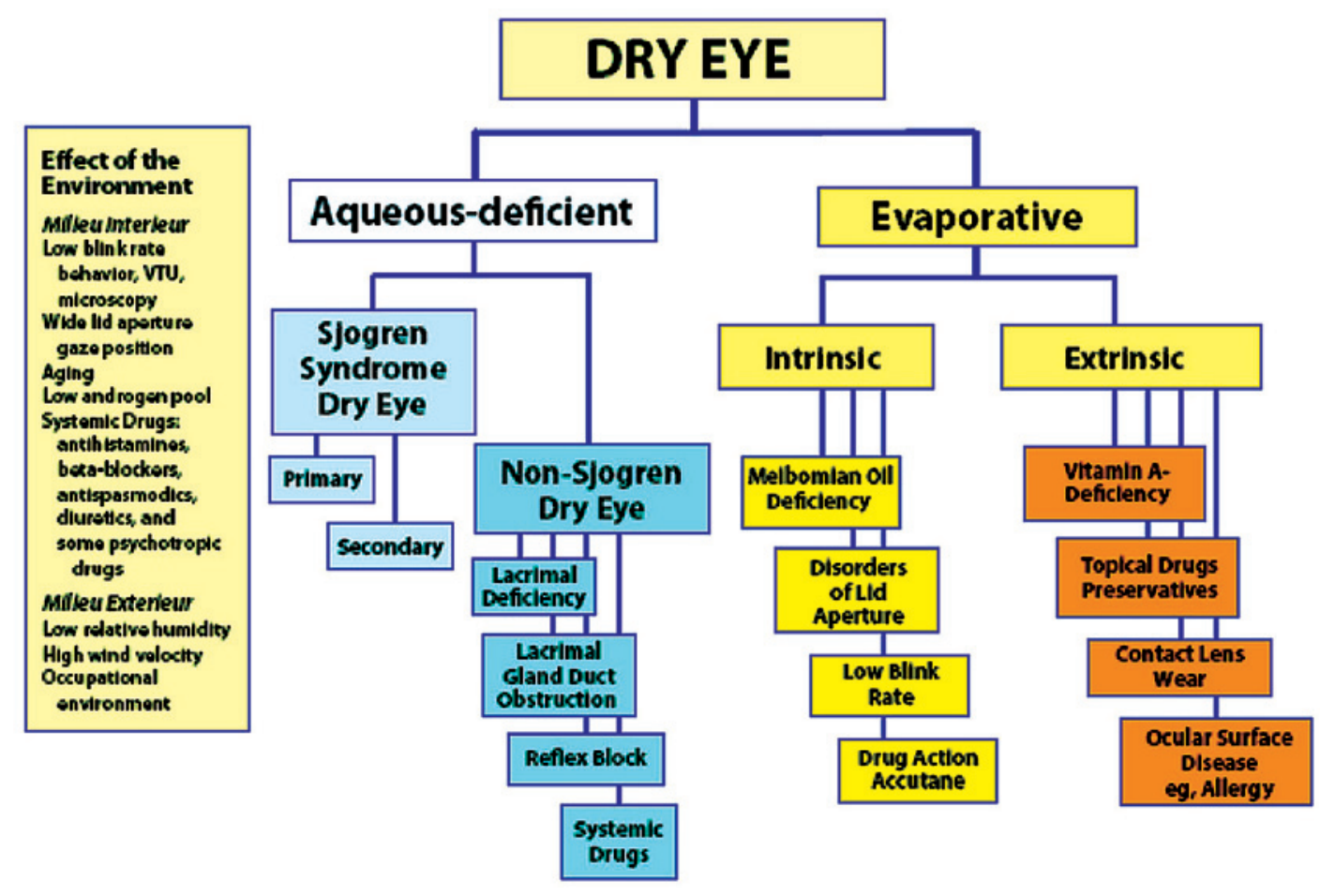

Figura 3 - Classificação de Olho Seco (DEWS) 
A disfunção de glândulas de Meibômio é mais comum em pacientes portadores de síndrome de Sjögren do que na população normal; portanto, uma deficiência da camada lipídica pode ainda contribuir para o olho seco devido ao excesso de evaporação(17).

$\mathrm{Na}$ deficiência aquosa não relacionada à síndrome de Sjögren existe uma disfunção lacrimal na ausência de manifestações sistêmicas de doença autoimune. As principais formas encontradas são:

\section{Deficiência primária da glândula lacrimal:}

- Olho seco relacionado à idade: é a mais comum; geralmente causada por obstrução dos ductos. O estresse oxidativo também está envolvido nesse processo, representado pelo acúmulo de lipofuscina nas células acinares das glândulas lacrimais ${ }^{(11,18-19)}$

- Alacrima congênita: causa rara de olho seco em jovens, determinada por mutação no gene que codifica a proteína ALADIN, responsável pelo transporte de RNA e/ou proteínas entre o núcleo e o citoplasma; aparece também como parte de outras síndromes, como a síndrome do triplo A (síndrome de Allgrove), doença de Addison, neurodegeneração central e disfunção autonômica.

- Disautonomia familiar (síndrome de Riley Day): doença autossômica recessiva caracterizada por insensibilidade à dor e ausência de reflexos emocional e lacrimal, resultantes de inervação anormal simpática e parassimpática da glândula lacrimal.

\section{Deficiência secundária da glândula lacrimal:}

- Infiltração inflamatória da glândula, como ocorre na sarcoidose, no linfoma, na AIDS, na amiloidose, na hemocromatose e em doenças infecciosas.

- Doença enxerto-hospedeiro, geralmente após transplante de células-tronco hematopoiéticas (GVHD "graft versus host disease" - doença do enxerto contra o hospedeiro): ocorre após transplante de medula óssea principalmente o alogênico.

- Ablação da glândula lacrimal

- Denervação parassimpática da glândula lacrimal

\section{Obstrução dos ductos da glândula lacrimal:}

- Pode ser causada por tracoma, penfigóide cicatricial e de membrana mucosa, eritema multiforme, queimaduras químicas ou térmicas e após terapia radioativa.

\section{Hipossecreção reflexa:}

\section{Bloqueio dos reflexos sensoriais}

A diminuição do estímulo sensorial a partir da superfície ocular pode favorecer a ocorrência de olho seco de duas maneiras - redução da secreção reflexo-induzida e redução da frequência de piscar, levando à evaporação. Os principais fatores de risco à hiposecreção reflexa são o uso crônico de lentes de contato, levando à hipoestesia da córnea; diabetes mellitus, em associação à neuropatia autonômica ou senso- rial e alterações microvasculares na glândula lacrimal; ceratite neurotrófica, com denervação sensorial do segmento anterior causada pela ação do herpes zoster oftálmico no nervo trigêmio. Além disso, atualmente é crescente o número de casos de olho seco relacionados à cirurgia refrativa, especialmente o LASIK (Laser in situ keratomileusis); acredita-se que o trauma aos nervos corneanos durante o procedimento inibe os impulsos nervosos que partem da superfície ocular dirigindose ao cérebro e retornando às glândulas lacrimais ${ }^{(20)}$.

\section{Bloqueio dos reflexos motores}

Um dano central ao VII nervo craniano, envolvendo o nervo intermédio que contém fibras parassimpáticas originadas no gânglio pterigopalatino, leva à hiposecreção lacrimal e fechamento palpebral incompleto. Dentre as condições associadas a este tipo de hiposecreção destacam-se a neuromatose múltipla e o uso de medicações sistêmicas, principalmente anti-histamínicos, betabloqueadores, antiespasmódicos, diuréticos, antidepressivos tricíclicos, inibidores da recaptação de serotonina e outros psicóticos.

O estado evaporativo está relacionado a:

\section{Fatores intrínsecos}

- Disfunção das glândulas de Meibômio: considerada a causa mais comum de olho seco evaporativo ${ }^{(21-22)}$. Está associada a várias condições, como acne rosácea, dermatite seborréica, dermatite atópica e uso de isotretinoína em tratamentos dermatológicos (Figura 4).

- Desordens do fechamento palpebral, inclusive as resultantes de blefaroplastia; com o aumento do número de cirurgias estéticas palpebrais as queixas características do quadro de olho seco têm se tornado mais frequentes, sendo decorrentes
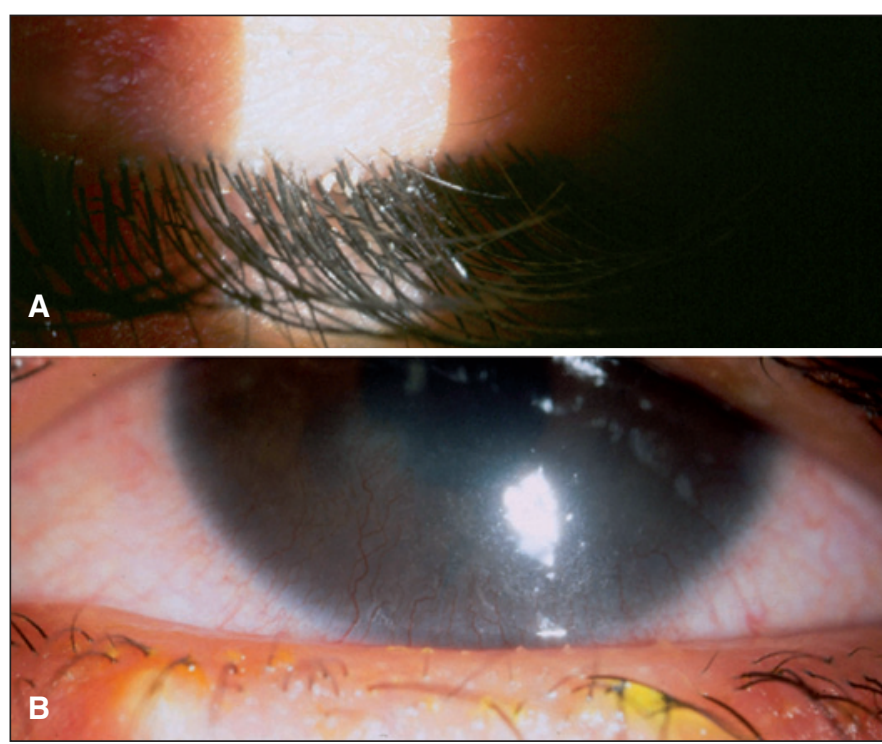

Figura 4 - Aspecto das pálpebras com disfunção de glândulas de Meibomius. 0 exame mostra crostas em cílios, material espesso na saída das glândulas de Meibomius, hiperemia da borda palpebral e neovascularização da região inferior da córnea. 
principalmente de alterações da fissura palpebral e da excursão da pálpebra superior ${ }^{(23)}$. Também nos quadros de proptose na doença ocular tireoideana pode haver evaporação excessiva da lágrima devido à exposição da superfície ocular.

- Baixa frequência do piscar

- Ação de drogas sistêmicas.

\section{Fatores extrínsecos}

- Deficiência de vitamina $\mathrm{A}^{(24)}$

- Medicações tópicas e conservantes ${ }^{(25)}$

- Uso de lentes de contato ${ }^{(26-27)}$

- Doenças da superfície ocular, especialmente conjuntivite alérgica.

Com relação aos fatores ambientais, distinguem-se os internos e os externos. Os internos caracterizam-se por baixa frequência do piscar, fenda palpebral ampla, posição do olhar, idade, baixo "pool" de androgênio e medicações sistêmicas, tais como: anti-histamínicos, betabloqueadores, antiespasmódicos, diuréticos e alguns psicotrópicos. Fatores externos compreendem: baixa umidade do ar, alta velocidade dos ventos e ambiente ocupacional.

\section{DIAGNóstico}

O grau de gravidade do olho seco pode ser avaliado através de uma tabela adaptada a partir daquela desenvolvida pelo Delphi Panel Report em 2007(1) ${ }^{(T a b e l a ~ 1) . ~ E l a ~ c l a s s i f i c a ~ a ~}$ gravidade da doença através de sinais e sintomas e alterações da superfície ocular, por meio da biomicroscopia e de testes específicos, como Schirmer e tempo de ruptura do filme lacrimal (TRFL ou, do inglês, tear film break-up time, BUT).

No que se refere ao diagnóstico, além de história clínica e questionários ${ }^{(28-29)}$ para avaliar sinais e sintomas, vários ou- tros testes podem ser aplicados ${ }^{(30-34)}$ para analisar estabilidade do filme lacrimal, superfície ocular e produção/evaporação de lágrima:

- TRFL

- Análise da altura ou espessura do menisco lacrimal

- Coloração da superfície ocular com fluoresceína, rosa bengala e lisamina verde

- Teste de Schirmer

- Avaliação da morfologia e padrão de secreção das glândulas de Meibômio

- Citologia de impressão, entre outros.

Para diagnosticar síndrome de Sjögren seguindo orientações de consensos internacionais e suas implicações sistêmicas são também utilizados testes laboratoriais para identificação de autoanticorpos (FAN: Fator antinúcleo, anti-Ro e antiLa) e biópsia de glândula lacrimal e glândulas salivares menores. O pouco uso desses métodos na prática se deve ao baixo valor preditivo dos autoanticorpos e a alta invasibilidade das biópsias ${ }^{(35)}$.

\section{TRATAMENTO}

O tratamento da síndrome do olho seco é predominantemente sintomático, ainda que medidas anti-inflamatórias, secretagogos e outras estratégias estejam em uso ou em estudo ${ }^{(36)}$. O DEWS, novamente baseando-se no painel Delphi, propõe diferentes métodos, de acordo com a gravidade da doença. Eles variam desde educação ao paciente até o uso de medicações tópicas e sistêmicas. Dentre as tópicas destacamse as lágrimas artificiais, os anti-inflamatórios (não hormonais, corticosteróides, ciclosporina A) e o soro autólogo. Medicações de uso sistêmico incluem ômega-3, tetraciclina, secretagogos e anti-inflamatórios.

\begin{tabular}{|c|c|c|c|c|}
\hline Gravidade do olho seco & 1 & 2 & 3 & 4 \\
\hline $\begin{array}{l}\text { Desconforto, } \\
\text { gravidade e } \\
\text { frequência }\end{array}$ & $\begin{array}{c}\text { Leve e/ou episódico; } \\
\text { ocorre sob estresse } \\
\text { ambiental }\end{array}$ & $\begin{array}{l}\text { Episódico moderado } \\
\text { ou crônico; com ou } \\
\text { sem estresse }\end{array}$ & $\begin{array}{c}\text { Grave frequente } \\
\text { ou constante; } \\
\text { sem estresse }\end{array}$ & $\begin{array}{c}\text { Grave e/ou incapacitante } \\
\text { e constante }\end{array}$ \\
\hline Sintomas visuais & $\begin{array}{l}\text { Ausentes } \\
\text { ou episódicos } \\
\text { leves }\end{array}$ & $\begin{array}{l}\text { Incomodam ou } \\
\text { limitam atividades; } \\
\text { episódicos }\end{array}$ & $\begin{array}{c}\text { Incomodam, limitam } \\
\text { atividades } \\
\text { constantemente } \\
\text { e/ou cronicamente }\end{array}$ & $\begin{array}{c}\text { Constante e/ou } \\
\text { possivelmente } \\
\text { incapacitante }\end{array}$ \\
\hline Injeção conjuntival & Ausente ou leve & Ausente ou leve & $+/-$ & $+/++$ \\
\hline Coloração conjuntival & Ausente ou leve & Variável & Moderada a acentuada & Acentuada \\
\hline Coloração corneal & Ausente ou leve & Variável & Acentuada central & Erosões puntactas graves \\
\hline $\begin{array}{l}\text { Sinais em córnea e } \\
\text { lágrima }\end{array}$ & Ausentes ou leves & $\begin{array}{l}\text { Debris leves, } \\
\downarrow \text { menisco }\end{array}$ & $\begin{array}{l}\text { Ceratite filamentar, } \\
\text { adesão de muco, } \\
\uparrow \text { debris lacrimais }\end{array}$ & $\begin{array}{c}\text { Ceratite filamentar, } \\
\text { adesão de muco, } \\
\uparrow \text { debris lacrimais, ulceração }\end{array}$ \\
\hline $\begin{array}{l}\text { Pálpebras/Glândulas } \\
\text { meibomianas }\end{array}$ & $\begin{array}{c}\mathrm{DGM}^{*} \\
\text { variavelmente presente }\end{array}$ & $\begin{array}{c}\mathrm{DGM}^{*} \\
\text { variavelmente presente }\end{array}$ & Frequente & $\begin{array}{l}\text { Triquíase, queratinização, } \\
\text { simbléfaro }\end{array}$ \\
\hline TFBUT $^{\star *}$ & Variável & $\leq 10$ & $\leq 5$ & Imediato \\
\hline Schirmer (mm/5min) & Variável & $\leq 10$ & $\leq 5$ & $\leq 2$ \\
\hline
\end{tabular}


Quando houver falha no tratamento instituído, deve-se observar se esta ocorreu por incompreensão, não aderência às recomendações ou agravamento transitório das condições ambientais. Nessas condições, uma revisão da estratégia é recomendada, antes da intensificação (Tabela 2).

Estão descritos para casos graves e resistentes ao tratamento o uso de lentes de contato esclerocorneanas, oclusão de pontos lacrimais e diversas técnicas cirúrgicas. Dentre elas estão a tarsorafia, enxerto de membrana mucosa, transposição do ducto da glândula salivar e transplante de membrana amniótica e de glândula salivar. É importante observar que muitas dessas técnicas não possuem avaliações comparativas por estudos clínicos ou de longo prazo ${ }^{(37)}$.

\section{DISCUSS ÃO}

Por tratar-se de uma condição que envolve muitas variáveis, torna-se difícil uma caracterização epidemiológica fidedigna, mesmo porque muitos casos deixam de ser diagnosticados apropriadamente, sendo tratados apenas os sintomas. Os consensos mais recentes têm colaborado no sentido de uniformizar os critérios diagnósticos, o que talvez possibilite futuramente um melhor entendimento epidemiológico da doença.

Com relação ao tratamento, os lubrificantes ou lágrimas artificiais são aprovadas para o uso sem necessidade de comprovação de eficácia clínica, de acordo com normas do Food and Drug Administration (FDA), órgão que regula as medicações nos Estados Unidos e serve de modelo para outros países, inclusive da Europa e Brasil. A superioridade de um lubrificante em

\begin{tabular}{|c|c|}
\hline $\begin{array}{l}\text { Classificação } \\
\text { de gravidade }\end{array}$ & Tratamento* \\
\hline 1 & $\begin{array}{l}\text { Educação; modificações ambientais e dietéticas } \\
\text { Eliminação de medicações sistêmicas } \\
\text { Lágrimas artificiais, géis } \\
\text { Tratamento de afecções das pálpebras }\end{array}$ \\
\hline 2 & $\begin{array}{l}\text { Quando tratamentos propostos } \\
\text { para grau } 1 \text { forem ineficazes, associar: } \\
\text { Anti-inflamatórios, tetraciclinas, secretagogos } \\
\text { Oclusão de ponto lacrimal } \\
\text { Óculos que retêm umidade }\end{array}$ \\
\hline 3 & $\begin{array}{l}\text { Quando tratamentos propostos } \\
\text { para grau } 2 \text { forem inadequados, associar: } \\
\text { Soro autólogo } \\
\text { Lentes de contato } \\
\text { Oclusão permanente de ponto lacrimal }\end{array}$ \\
\hline 4 & $\begin{array}{l}\text { Quando tratamentos propostos } \\
\text { para grau } 3 \text { forem inadequados, associar: } \\
\text { Anti-inflamatórios sistêmicos } \\
\text { Cirurgia (pálpebras, membrana mucosa, glândula } \\
\text { salivar, transplante de membrana amniótica) }\end{array}$ \\
\hline
\end{tabular}

relação a outro de proteger a superfície ocular e aliviar os sintomas, sugerida nas propagandas, não foi necessariamente comprovada em estudos clínicos controlados e talvez não exista método clínico satisfatoriamente sensível para indicar a superioridade de um sobre o outro. Por outro lado, medicações com ingredientes ativos (por exemplo: anti-inflamatórios, vitaminas, secretagogos, etc.) requerem, para sua liberação para o comércio, comprovação de eficácia frente a um placebo, com desenho, planejamento e execução adequados e superioridade em pelo menos um sintoma e um sinal relacionados ao olho $\operatorname{seco}^{(38-39)}$. Com tudo isso, se estima que haja no mundo cerca de 100 medicações diferentes em uso para olho seco e o International Market Survey, em 2003, indicou que entre os 750 milhões de frascos de colírio vendidos naquele ano, quase 120 milhões eram para olho seco. Ainda assim, investimentos em novos e melhores produtos são potencialmente rentáveis e indicações de mudanças futuras nas estratégias podem ser observadas pelas patentes depositadas na última década ${ }^{(40)}$.

Anualmente inúmeros ensaios clínicos randomizados publicados com foco no tratamento do olho seco: comparações entre lágrimas artificiais de diferentes viscosidades uso de lágrimas artificiais em contraste com outras modalidades de tratamento como oclusão de pontos lacrimais, ciclosporina, medicações sistêmicas, entre outras.

Apesar de todas as pesquisas que visam elucidar os fatores etiológicos e fisiopatológicos envolvidos na síndrome do Olho Seco, o tratamento ainda permanece desafiador, sendo necessário se estabelecer o que é realmente seguro e eficaz no manejo do crescente número de portadores.

\section{ABSTRACT}

Dry eye is a multifactorial disease of tears and ocular surface that causes discomfort, visual disturbance and tear film instability. It is a common disorder that affects specially adults and women and can cause quality of life impairment comparable to migraine, shortness of breath and chronic renal insufficiency, depending on its symptoms or complications. New concepts regarding physiopathology, classification and treatment have been presented and should be known by ophthalmologists because of their relevance on day-by-day application. There are about 100 different medications currently in use for dry eye besides other methods of treatment, so it is necessary to establish what is really safe and effective for dry eye. This paper presents a review about Dry Eye Syndrome etiopathogenesis and treatment.

Keywords: Dry eye syndrome/therapy; keratoconjuntivitis sicca/therapy; Cornea disease/therapy

\section{REFERÊNCIAS}

1. Dry Eye Workshop (DEWS) Committee. 2007 Report of the Dry Eye Workshop (DEWS). Ocul Surf. 2007;5(2):65-204. 
2. Murube J. Tear osmolarity. Ocul Surf. 2006;4(2):62-73. Review.

3. Tomlinson A, Khanal S, Ramaesh K, Diaper C, McFadyen A. Tear film osmolarity: determination of a referent for dry eye diagnosis. Invest Ophthalmol Vis Sci. 2006;47(10):4309-15.

4. Schein OD, Hochberg MC, Muñoz B, Tielsch JM, Bandeen-Roche K, Provost $\mathrm{T}$, et al. Dry eye and dry mouth in the elderly: a population-based assessment. Arch Intern Med. 1999;159(12):1359-63. Comment in: Arch Intern Med. 2001; 161(4):615.

5. Muñoz B, West SK, Rubin GS, Schein OD, Quigley HA, Bressler SB, Bandeen-Roche K. Causes of blindness and visual impairment in a population of older Americans: The Salisbury Eye Evaluation Study. Arch Ophthalmol. 2000;118(6):819-25.

6. Butovich IA, Millar TJ, Ham BM. Understanding and analyzing meibomian lipidsa review. Curr Eye Res. 2008;33(5):405-20.

7. Chen HB, Yamabayashi S, Ou B, Tanaka Y, Ohno S, Tsukahara S. Structure and composition of rat precorneal tear film. A study by an in vivo cryofixation. Invest Ophthalmol Vis Sci. 1997;38(2):381-7.

8. Stern ME, Beuerman RW, Fox RI, Gao J, Mircheff AK, Pflugfelder SC. The pathology of dry eye: the interaction between the ocular surface and lacrimal glands. Cornea. 1998;17(6):584-9.

9. Stern ME, Gao J, Siemarko KF, Beuerman RW, Pflugfelder SC. The role of the lacrimal functional unit in the pathophysiology of dry eye. Exp Eye Res. 2004;78(3):409-16. Review.

10. Farris RL. Tear osmolarity a new gold standard? Adv Exp Med Biol. 1994; 350:495-503.

11. Wakamatsu TH, Dogru M, Tsubota K. Tearful relations: oxidative stress, inflammation and eye diseases. Arq Bras Oftalmol. 2008;71(6 Suppl):72-9

12. Módulo CM, Jorge AG, Dias AC, Braz AM, Bertazolli-Filho R, Jordão AA Jr, et al. Influence of insulin treatment on the lacrimal gland and ocular surface of diabetic rats. Endocrine. 2009;36(1):161-8.

13. Murube J, Németh J, Höh H, Kaynak-Hekimhan P, Horwath-Winter J, Agarwal A, et al. The triple classification of dry eye for practical clinical use. Eur $\mathbf{J}$ Ophthalmol. 2005;15(6):660-7.

14. Li DQ, Chen Z, Song XJ, Luo L, Pflugfelder SC. Stimulation of matrix metalloproteinases by hyperosmolarity via a JNK pathway in human corneal epithelial cells. Invest Ophthalmol Vis Sci. 2004;45(12):4302-11.

15. Dawson LJ, Stanbury J, Venn N, Hasdimir B, Rogers SN, Smith PM. Antimuscarinic antibodies in primary Sjögren's syndrome reversibly inhibit the mechanism of fluid secretion by human submandibular salivary acinar cells. Arthritis Rheum. 2006;54(4):1165-73.

16. Vitali C, Bombardieri S, Jonsson R, Moutsopoulos HM, Alexander EL, Carsons SE, Daniels TE, Fox PC, Fox RI, Kassan SS, Pillemer SR, Talal N, Weisman MH; European Study Group on Classification Criteria for Sjögren's Syndrome. Classification criteria for Sjögren's syndrome: a revised version of the European criteria proposed by the American-European Consensus Group. Ann Rheum Dis. 2002;61(6):554-8.

17. Shimazaki J, Goto E, Ono M, Shimmura S, Tsubota K. Meibomian gland dysfunction in patients with Sjögren's syndrome. Ophthalmology. 1998;105(8): 1485-8.

18. Damato BE, Allan D, Murray SB, Lee WR. Senile atrophy of the human lacrimal gland: the contribution of chronic inflammatory disease. Br J Ophthalmol. 1984;68(9):674-80.

19. Craig JP, Tomlinson A. Age and gender effects on the normal tear film. Adv Exp Med Biol. 1998;438:411-5.

20. Durie D, Stahl J. A randomized clinical evaluation of the safety of Systane Lubricant Eye Drops for the relief of dry eye symptoms following LASIK refractive surgery. Clin Ophthalmol. 2008;2(4):973-9.
21. Foulks GN, Bron AJ. Meibomian gland dysfunction: a clinical scheme for description, diagnosis, classification, and grading. Ocul Surf. 2003;1(3):107-26.

22. Bron AJ, Tiffany JM. The contribution of meibomian disease to dry eye. Ocul Surf. 2004;2(2):149-65.

23. Lima CGMG, Siqueira GB, Cardoso IH, Sant'Anna AEB, Osaki MH. Avaliação do olho seco no pré e pós-operatório de blefaroplastia. Arq Brasil Oftalmol. 2006;69(2):227-32

24. Tei M, Spurr-Michaud SJ, Tisdale AS, Gipson IK. Vitamin A deficiency alters the expression of mucin genes by the rat ocular surface epithelium. Invest Ophthalmol Vis Sci. 2000;41(1):82-8.

25. Pisella PJ, Pouliquen P, Baudouin C. Prevalence of ocular symptoms and signs with preserved and preservative free glaucoma medication. Br J Ophthalmol. 2002;86(4):418-23.

26. Nichols JJ, Mitchell GL, Nichols KK, Chalmers R, Begley C. The performance of the contact lens dry eye questionnaire as a screening survey for contact lensrelated dry eye. Cornea. 2002;21(5):469-75

27. Glasson MJ, Stapleton F, Keay L, Sweeney D, Willcox MD. Differences in clinical parameters and tear film of tolerant and intolerant contact lens wearers. Invest Ophthalmol Vis Sci. 2003;44(12):5116-24.

28. Schiffman RM, Christianson MD, Jacobsen G, Hirsch JD, Reis BL. Reliability and validity of the Ocular Surface Disease Index. Arch Ophthalmol. 2000;118(5): 615-21. Comment in: Arch Ophthalmol. 2001;119(3):456.

29. Begley CG, Caffery B, Chalmers RL, Mitchell GL; Dry Eye Investigation (DREI) Study Group. Use of the dry eye questionnaire to measure symptoms of ocular irritation in patients with aqueous tear deficient dry eye. Cornea. 2002; 21(7):664-70.

30. Farris RL, Stuchell RN, Mandel ID. Basal and reflex human tear analysis. I. Physical measurements: osmolarity, basal volumes, and reflex flow rate. Ophthalmology. 1981;88(8):852-7.

31. Goren MB, Goren SB. Diagnostic tests in patients with symptoms of keratoconjunctivitis sicca. Am J Ophthalmol. 1988;106(5):570-4.

32. Yokoi N, Komuro A. Non-invasive methods of assessing the tear film. Exp Eye Res. 2004;78(3):399-407.

33. Tomlinson A, Khanal S, Ramaesh K, Diaper C, McFadyen A. Tear film osmolarity: determination of a referent for dry eye diagnosis. Invest Ophthalmol Vis Sci. 2006;47(10):4309-15.

34. van Bijsterveld OP. Diagnostic tests in the Sicca syndrome. Arch Ophthalmol. 1969;82(1):10-4

35. Hay EM, Thomas E, Pal B, Hajeer A, Chambers H, Silman AJ. Weak association between subjective symptoms or and objective testing for dry eyes and dry mouth: results from a population based study. Ann Rheum Dis. 1998; 57(1):20-4.

36. Rocha EM, Rocha FJ, Kara José Júnior N, Aguilar AJ. Olho seco. In: Gomes JAP, Alves MR, organizadores. Superfície ocular. Rio de Janeiro: Cultura Médica; 2006. p.57-68.

37. Management and therapy of dry eye disease: report of the Management and Therapy Subcommittee of the International Dry Eye WorkShop (2007). Ocul Surf. 2007;5(2):163-78.

38. Foulks GN. Challenges and pitfalls in clinical trials of treatments for dry eye. Ocul Surf. 2003;1(1):20-30.

39. Design and conduct of clinical trials: report of the Clinical Trials Subcommittee of the International Dry Eye WorkShop. Ocul Surf. 2007;5(2):153-62.

40. McDonald CC, Kaye SB, Figueiredo FC, Macintosh G, Lockett C. A randomised, crossover, multicentre study to compare the performance of $0,1 \%(\mathrm{w} / \mathrm{v})$ sodium hyaluronate with $1,4 \%(\mathrm{w} / \mathrm{v})$ polyvinyl alcohol in the alleviation of symptoms associated with dry eye syndrome. Eye (Lond). 2002;16(5):601-7. 